\title{
Sentidos de Doença Mental em um Grupo Terapêutico e suas Implicações ${ }^{1}$
}

\author{
Carla Guanaes \\ Centro Universitário Barão de Mauá \\ Centro de Formação Profissional \\ Marisa Japur ${ }^{2}$ \\ Universidade de São Paulo - Ribeirão Preto
}

\begin{abstract}
RESUMO - Este estudo adota uma perspectiva construcionista social, que focaliza o modo como as pessoas constroem sentidos de si mesmas e de mundo em suas práticas discursivas. Enfatizando o caráter performático da linguagem, objetivou-se, nesta pesquisa, descrever alguns sentidos de doença mental produzidos em um grupo terapêutico realizado em um ambulatório de saúde mental, e as implicações do uso destes sentidos para as conversações grupais. Baseada na transcrição das 16 sessões do grupo, a análise da produção de sentidos permitiu a descrição de alguns sentidos de doença mental, bem como a construção de relações entre estes sentidos, a visão de mudança e os modos de interação por estes favorecidos. Através dessa análise, apontamos a utilidade de refletir sobre as implicações do uso de determinados sentidos de doença mental em terapia de grupo, como uma forma de potencializar as trocas dialógicas entre os participantes e a construção conversacional da mudança.
\end{abstract}

Palavras-chave: construcionismo social; terapia de grupo; saúde mental.

\section{Implications of Mental Illness Meanings in a Therapeutic Group}

\begin{abstract}
This study adopts a social constructionist perspective, which focuses on how people make meaning of themselves and of the world in their discursive practices. By emphasizing the performative character of language, the aim of this study was to describe meanings of mental illness produced in a therapeutic group, offered in a mental health ambulatory, and the implications of the use of these meanings to the group conversations. The meaning making analysis was based on the transcriptions of 16 group sessions. This analysis allowed us to describe some meanings of mental illness, to construct links among these meanings and the changing view favored by them, as well as the interaction among the group participants. Based on this, we suggest that thinking about some mental illness meanings and its use can be useful to promote dialogical exchanges in group therapy and the conversational construction of change.
\end{abstract}

Key words: social constructionism; group therapy; mental health.

Este estudo adota uma perspectiva construcionista social, que se caracteriza como uma forma de investigação que dá ênfase ao modo como as pessoas, através de sua participação em práticas discursivas social, histórica e culturalmente situadas, constroem sentidos de mundo e de si mesmas (Gergen, 1997). Numa perspectiva construcionista social, entende-se que o sentido é construído pelas pessoas numa ação-conjunta e de uso corporificado da linguagem (Shotter, 2000). Destaca-se, assim, a função da linguagem e dos relacionamentos humanos na construção do mundo. Vista como linguagem em uso, a linguagem é considerada em seu caráter performático, isto é, em seu poder constituinte das realidades conversacionais através das quais as pessoas criam e sustentam práticas sociais e modos de agir no mundo.

Buscando descrever o modo como se dá o processo de produção de sentidos, Spink e Medrado (1999) adotam uma proposta temporal, na qual tanto os processos microssociais e situados de produção de sentidos, como a influência do contexto social, histórico e cultural têm lugar de destaque.

1 Apoio: FAPESP/CNPq.

2 Endereço: Universidade de São Paulo, Departamento de Psicologia e Educação, Av. Bandeirantes, 3900, Ribeirão Preto, SP, Brasil 14040901.E-mail: mjapur@ffclrp.usp.brou ou carla_guanaes@yahoo.com
Segundo os autores, a produção de sentidos acontece numa interação situada entre interlocutores (tempo curto), sendo também influenciada pelas possibilidades de significação de uma dada comunidade lingüística (tempo longo) e pela história conversacional (tempo vivido) dos interlocutores que participam desta interação. Portanto, embora local e situado, o processo de produção de sentidos é também marcado por discursos sociais, referentes tanto às experiências individuais de socialização, como à participação das pessoas em uma cultura na qual alguns discursos e modos de fala são valorizados.

Se observarmos as conversas das pessoas em seu cotidiano, as manchetes de jornais, as interações de personagens nas telenovelas, veremos que muitos dos discursos sociais acerca da doença mental, produzidos em períodos históricos específicos, participam, ainda hoje, dos modos pelos quais as pessoas dão sentido às suas vidas e relacionamentos. Ser doente mental, louco, problemático, perturbado, nervoso, pinel, desregulado, desequilibrado, ruim da cabeça, por exemplo, são termos que tiveram origem em momentos históricos específicos, mas são, ainda hoje, modos comuns pelos quais as pessoas referem-se ao portador de uma doença mental. As pessoas fazem uso destas e de outras descrições sempre que se defrontam com situações em que estas podem ajudá-las a dar sentido a suas experiências de vida e relacionamentos. 
Em nossa cultura, diversos discursos sociais têm sustentado a construção da doença mental como um fenômeno complexo e de difícil entendimento. Este sentido foi sendo construído tanto a partir do conhecimento científico, através das contribuições da Psiquiatria, Psicanálise e Psicologia, como da sabedoria de senso comum que, além de seus próprios conhecimentos, apropriou-se também dos discursos da ciência, ressignificando-os e utilizando-os na construção de diferentes entendimentos sobre a doença mental e suas formas de tratamento.

Descrever os diversos modos pelos quais a doença mental tem sido descrita ao longo dos anos na cultura ocidental tem sido objeto de estudo de autores como Foucault (1994/1954; 1995/1961) e Pessotti (1994, 1996). Estes estudos contribuem com uma reflexão crítica sobre a produção de conhecimento neste campo, dando visibilidade à diversidade de sentidos sobre o adoecimento mental construída ao longo da história e à participação dos discursos médico e psicológico nesta construção.

Não pretendemos, aqui, fazer uma ampla revisão sobre os sentidos de doença mental construídos ao longo das épocas, primeiro por considerarmos este um campo já bastante explorado e discutido (Foucault, 1994/1954, 1995/1961; Pessotti, 1994, 1996) e, segundo, porque esta tarefa foge aos objetivos deste estudo. Assumindo a distinção marcada por Spink e Medrado (1999) entre discurso (uso institucionalizado da linguagem) e prática discursiva (produção situada de sentidos, nos momentos ativos de uso da linguagem), este estudo focaliza o entendimento das práticas discursivas e, portanto, do processo situado de produção de sentidos de doença mental, em um grupo de curta duração. Contudo, uma breve apresentação de alguns discursos sociais que têm atravessado a construção de sentidos de doença mental fazse importante neste estudo, permitindo rastrear um campo de significação ao qual também os participantes do grupo aqui estudado recorreram em suas conversações.

Retomando a história do conhecimento em Psiquiatria, Pessotti (1994) aponta que "a concepção de loucura como envolvendo um estado ou processo unitário, mais ou menos duradouro ou complexo, envolvendo disfunções orgânicas e afetivas, é relativamente recente na história do conhecimento" (p. 9). Anteriormente a esta definição, uma multiplicidade de descrições se produziu, marcadas ora por acentuado misticismo e abstração, ora por grande concretude e organicidade.

Antes da emergência desse enfoque médico/científico (séculos XVII e XVIII), as descrições da loucura eram pautadas, sobretudo, por sentidos místicos e espirituais. Entendiam-se os comportamentos bizarros e desviantes e as alterações nos estados de humor como manifestações de bruxaria, de um espírito demoníaco ou de uma alma inquieta, sendo o exorcismo visto como prática curativa. Temor e medo faziam parte da relação das pessoas com a loucura, sendo a segregação e a marginalização social dos portadores da doença mental um resultado deste tipo de construção discursiva.

Um enfoque mais medicalizado sobre a loucura começou a emergir apenas a partir do século XVII. É neste século que surge o conceito de "alienação mental", termo que organizará parte da nosografia do século XIX (Pessotti, 1994). Através deste conceito, a loucura passou a ser vista como uma alteração que se processa na mente, traduzindo-se em comportamentos, delírios ou idéias, derivando de causas passionais ou internas.

A partir desse período, alternaram-se, na Psiquiatria, descrições da etiologia da doença mental tipicamente organicistas (ênfase nos aspectos anatomo-fisiológicos da doença), com descrições mais voltadas a seus aspectos afetivos e passionais. Estas ganharam destaque especialmente a partir do século XIX, a partir da obra de Pinel, que sustentava a origem passional ou moral da alienação, rompendo com as teorias organicistas precedentes. Para ele, as causas da alienação poderiam ser diversas, incluindo fatores hereditários, orgânicos ou morais, tais como "paixões, conflitos, frustrações, hábitos, gostos, vícios" (Pessotti, 1994, p. 165).

Contudo, como descreve Foucault (1995/1961), é inútil tentar distingüir as terapêuticas físicas das psicológicas até o século XIX, pois a Psicologia não existia neste período. Foi apenas a partir daquela época que houve uma separação entre a experiência da loucura e seu componente orgânico. Foucault atribui à Freud e a sua teoria psicanalítica o mérito de considerar a loucura em sua linguagem, dando voz à experiência que tinha sido calada pelo positivismo dos séculos anteriores e favorecendo uma reconfiguração do psicológico. Assimilando as contribuições psicodinâmicas de Freud, a Psiquiatria assumiu, então, um olhar mais ampliado sobre a loucura, estando atenta à linguagem e aos aspectos psicológicos e significativos de sua expressão.

No contexto específico das produções em Psicologia, diversas descrições sobre funcionamento mental, patologia e comportamento humano emergiram a partir disso, produzindo entendimentos que, disseminados pelo conhecimento científico, hoje fazem parte do senso comum, presentificando-se nas práticas discursivas cotidianas. Dentre eles, destacam-se: a relação entre doença mental e o retorno a estados primitivos; a noção de trauma e a importância das vivências passadas; a pressuposição de fases e estágios de desenvolvimento normal; a noção de mundo mental, marcado por construções simbólicas, seguida da noção de conflitos internos e ambivalência afetiva; a importância das relações familiares e das interações sociais em geral, considerando a influência do meio no desenvolvimento da doença; e referências a problemas vividos nos processos de socialização e aprendizagem de normas e regras sociais.

Atualmente, caminha-se em direção a um entendimento mais ampliado da doença mental, entendendo ser esta resultante de diversos fatores - orgânicos, emocionais, genéticos, culturais, sociais, situacionais, entre outros. Busca-se, assim, uma visão menos reducionista da mesma, quando uma atenção ao bem-estar físico e psicológico do paciente é considerada fundamental. Expandindo-se as significações, expandem-se também as modalidades de tratamento. Nos serviços de atendimento em saúde mental, formas de atenção também mais amplas vêm sendo propostas, contando com a participação de diversos profissionais - psiquiatras, psicólogos, assistentes sociais, terapeutas ocupacionais, entre outros. Busca-se, assim, um tratamento mais humanitário que responda à complexidade das possíveis causas do adoecimento.

Partindo das contribuições da perspectiva construcionista social, é importante destacar que descrever a doença mental 
de uma ou outra forma não é um processo inócuo. Estas descrições são criações de uma cultura, sendo entendidas como práticas sociais. Através delas, determinados modos de intervenção são propostos, identidades construídas e formas de vida sustentadas.

Refletindo sobre estas questões em um nível social mais amplo, vemos, por exemplo, que a proposta de Pinel de compreensão da loucura como tendo origem passional ou moral esteve associada à descrição dos loucos como seres irracionais e passionais, e foi seguida da proposição do tratamento moral, pautado em uma severa e brutal disciplina. Ao contrário, a descrição da doença mental como tendo uma origem demoníaca, favorecia a construção do louco como um ser acometido ou possuído por espíritos ou almas inquietas, sendo seguida do exorcismo como técnica curativa. Do mesmo modo, as explicações atuais sobre a doença mental possibilitam diferentes descrições identitárias e sustentam, também, determinadas formas de tratamento, tais como a conjugação de tratamentos medicamentosos e psicoterápicos e a evitação das internações hospitalares, que passa a ser indicada apenas em casos de grave crise, por períodos reduzidos de tempo.

Esta reflexão pode ser ampliada se estendida aos contextos locais, nos quais tais sentidos são ativamente nego- ciados pelas pessoas em suas interações (Guanaes, 2004). Aceitando o convite construcionista, mais do que investigar a veracidade das descrições de doença mental existentes ou buscar propor um novo entendimento da mesma, podemos refletir sobre o quê o uso destes sentidos de doença mental, em relacionamentos situados, gera. Que práticas sociais estes discursos sobre doença mental sustentam? Que formas de relacionamento promovem? Que identidades são construídas a partir destes modos de descrição? Estas questões, afinadas com a perspectiva construcionista social, representam uma visão pragmática e crítica de entendimento sobre a doença mental, e sustentam também a proposta deste estudo.

\section{Objetivos}

Buscamos, neste estudo, descrever alguns sentidos de doença mental produzidos por participantes de um grupo terapêutico. Considerando a ênfase construcionista no caráter performático da linguagem, buscamos, mais especificamente, explicitar as implicações do uso dos diferentes sentidos de doença mental para o fluxo conversacional imediato, especialmente em relação à construção de determinados sentidos de mudança e de modos de relacionamento entre os participantes do grupo.

Quadro 1. Condição dos participantes no momento de encaminhamento para o grupo, em relação a suas principais queixas, diagnósticos (CID-10), uso de medicação e tratamentos anteriores (Guanaes, 2000)

\begin{tabular}{|c|c|c|c|c|}
\hline Nomes $^{3}$ & Queixas & Diagnóstico & Medicação & Tratamentos anteriores \\
\hline Roberta & $\begin{array}{l}\text { Dificuldades de relacionamento conjugal, ambivalência } \\
\text { afetiva, desânimo e angústia }\end{array}$ & $\begin{array}{l}\text { Transtorno de } \\
\text { ansiedade }\end{array}$ & - & - \\
\hline João & $\begin{array}{l}\text { Mais calmo, situação familiar e profissional mais estável } \\
\text { Sem outras queixas }\end{array}$ & Transtorno adaptativo & - & $\begin{array}{l}\text { Participação em grupo } \\
\text { terapêutico }\end{array}$ \\
\hline Ana Maria & $\begin{array}{l}\text { Melhor em relação às queixas depressivas, mais animada } \\
\text { e disposta } \\
\text { Realizando atividades de trabalho e desejando voltar a } \\
\text { estudar e fazer pintura }\end{array}$ & $\begin{array}{l}\text { Transtorno depressivo } \\
\text { recorrente, episódio } \\
\text { atual moderado }\end{array}$ & Ansiolítica & Tratamento psiquiátrico \\
\hline Marta & $\begin{array}{l}\text { Dificuldades de relacionamento com a mãe; queixa-se de } \\
\text { desinteresse e incapacidade de procurar emprego }\end{array}$ & $\begin{array}{l}\text { Transtorno } \\
\text { esquizotímico }\end{array}$ & Antipsicótica & $\begin{array}{l}\text { Tratamento psiquiátrico } \\
\text { (internação em Hospital Dia) }\end{array}$ \\
\hline Marli & $\begin{array}{l}\text { Queixa-se de cabeça grande, irritabilidade, medo que algo } \\
\text { ruim lhe aconteça } \\
\text { Diz ficar contrariada sem motivo e ter insônia }\end{array}$ & Distimia & $\begin{array}{l}\text { Antidepressiva e } \\
\text { ansiolítica }\end{array}$ & $\begin{array}{l}\text { Tratamentos psiquiátrico } \\
\text { (11 internações). }\end{array}$ \\
\hline Irene & $\begin{array}{l}\text { Refere estar cansada das tarefas domésticas, dificuldade } \\
\text { para respirar e andar direito }\end{array}$ & Distimia & $\begin{array}{l}\text { Antidepressiva } \\
\text { e ansiolitica }\end{array}$ & Tratamento psiquiátrico \\
\hline Estela & $\begin{array}{l}\text { Refere pensar em se matar quando as coisas não dão certo, } \\
\text { mas nega planejar suicídio Quadro de escurecer a vista, } \\
\text { inapetência, perda de peso }\end{array}$ & $\begin{array}{l}\text { Ansiedade } \\
\text { generalizada }\end{array}$ & - & - \\
\hline Valter & $\begin{array}{l}\text { Sente náuseas, vômitos, indo em pânico para o hospital } \\
\text { acreditando ter hemorragia } \\
\text { Sono excessivo }\end{array}$ & $\begin{array}{l}\text { Ansiedade } \\
\text { generalizada }\end{array}$ & $\begin{array}{l}\text { Antidepressiva e } \\
\text { ansiolítica }\end{array}$ & - \\
\hline Rosilene & $\begin{array}{l}\text { Uso abusivo de tranqüilizantes, problemas de } \\
\text { relacionamento com o ex-marido } \\
\text { Ansiedade }\end{array}$ & $\begin{array}{l}\text { Transtorno } \\
\text { dissociativo }\end{array}$ & Ansiolítica & Tratamentos psiquiátricos \\
\hline Marília & $\begin{array}{l}\text { Melhor das queixas de ansiedade e depressão } \\
\text { Sem sintomas há sete anos e uso de medicação }\end{array}$ & Distimia & $\begin{array}{l}\text { Antidepressiva e } \\
\text { ansiolítica }\end{array}$ & - \\
\hline Leila & $\begin{array}{l}\text { Queixas de medo de andar de ônibus, de carro e de } \\
\text { elevador; medo de chuva; crises de diarréia; taquicardia }\end{array}$ & Fobia social & - & Tratamento psiquiátrico \\
\hline
\end{tabular}

3 Os nomes de todos os participantes do grupo, incluindo o terapeuta, são fictícios. 


\section{Método}

\section{Contexto e participantes}

Este estudo teve como base as transcrições das sessões de um grupo terapêutico, realizado em um ambulatório público de saúde mental de Ribeirão Preto. Este grupo teve 16 sessões de uma hora e meia de duração semanal, foi coordenado por um psiquiatra e observado pela primeira autora deste artigo. Participaram do grupo 11 pacientes - nove mulheres e dois homens, com idade entre 29 e 65 anos, a maioria casada, com primeiro grau incompleto e trabalhando em serviços domésticos. No Quadro 1, apresentamos uma breve descrição dos participantes em relação às queixas referidas no momento de encaminhamento para o grupo, a seus diagnósticos, ao uso de medicação e à história de tratamento psiquiátrico/psicológico anterior.

\section{Procedimentos de constituição e análise do corpus}

Todas as sessões do grupo foram audio-gravadas e transcritas na íntegra, acrescidas de notas de observação sobre as interações grupais (gestos, expressões, tonalidade afetiva). Também foi realizado um registro contendo informações médicas sobre cada participante, incluindo descrições de suas queixas, do uso de medicação e de seus diagnósticos. Estas notas foram utilizadas para descrição dos participantes e contextualização das conversas grupais no contexto institucional mais amplo. A análise da transcrição das sessões do grupo foi realizada através dos seguintes passos: a) leitura exaustiva das sessões do grupo; b) análise temática dos sentidos de doença mental em circulação nas trocas dialógicas grupais; c) análise das implicações do uso destes sentidos para o fluxo conversacional, incluindo a construção de sentidos de mudança e de modos de relacionamento entre os participantes do grupo; e d) escolha de algunhas vinhetas clínicas, ilustrativas das análises realizadas nos itens b e c.

\section{Resultados}

Apresentamos, a seguir, os sentidos de doença mental produzidos em nossa análise, seguidos de algumas vinhetas clínicas.

\section{a) A doença mental como decorrente de dificuldades vividas no passado.}

O sentido de que o problema ou doença atual é resultado de experiências de sofrimento do passado emergiu em diferentes momentos das conversações grupais, sendo mais prevalente nos relatos de Marta, Irene e Estela. Geralmente, derivava do uso deste sentido, a construção de longas narrativas, com estilo de relatos autobiográficos. Isto caracterizava um padrão interativo bastante peculiar, no qual a pessoa que narrava sua história de vida posicionava os demais como ouvintes silentes. Na maioria das vezes, a justificativa do problema ou doença atual por uma experiência de sofrimento vivida no passado criava poucas chances de participação grupal e de construção de expectativas de mudança nas conversações desenvolvidas neste contexto.
Exemplo: Na sessão 11, os participantes discutem os aspectos emocionais envolvidos na origem dos problemas. Roberta diz não entender o que tem, queixando-se de vários sintomas e de medo de andar de ônibus. Os participantes discutem as causas do medo e emerge a explicação de que este pode ter relação com vivências da infância.

Roberta: Mas eu acho que a infância influencia sim, quando a criança é muito sofrida de pequena, eu acho que fica sim. Porque meu menino mais velho tem 10 anos, quando eu tive ele... Ele tinha dois anos, mas eu judiava dele, batia, batia, não tinha paciência com ele, eu era nervosa, dava cada tapa na cabeça dele! (...) Ele também foi muito judiado, e hoje ele tem problema. Ele tem problema de aprendizagem, né, na escola, ele é muito nervoso, irritado. (...) E meu menino de sete anos, ele também faz tratamento com psicólogo, com fonoaudióloga e com neuro. Os dois. Porque quando ele tinha seis meses, ele ficou muito doente, ele ficou internado quase dois meses no hospital. (...) Foi um menino muito judiado, e quando ele saiu do hospital, ele ficou meio bobão, meio paradão, mas normal. (...) Pra você ver como é que é, os dois que foi mais judiados, um que foi judiado porque eи que judiei mais dele, que ficou traumatizado, e o outro pelo hospital. (...). Eu acho que tem sim, viu? Muitos problemas que a pessoa tá hoje é de muito tempo passado, eu acho que sim. É a mente, né? Problema emocional mesmo. Porque este meu menino de dez anos a psicóloga falou pra mim, que muito problema dele é problema emocional. Que é coisa de muito tempo. Só que eu não falei o que eu fiz, por isto que eu tô falando aqui, que eu fiz. Eu fui uma que quando eu era pequena eu não tinha vida boa não! Eu morei, quando eu era pequena, meus pais moravam em favela. Meus pais moravam em favela, eu passava fome, sabe? De pequena eu andava descalça, sabe? Nossa, eu não tinha nem o que vestir, a casa era aberta...

Terapeuta: Aqui em Ribeirão?

Roberta: Ribeirão. Xi! Eu morei aqui em favela muito tempo. (...) quando eu era pequena eu sofri sim, tinha vontade de ter as coisas e não tinha. Se eu via boneca, adorava boneca, não tinha boneca, tinha só aquelas bonecas que achava no lixo, assim, sabe? Faltando perna, cabeça (ri). Então é isto aí. Então, quando eu era pequena eu sofri muito e apanhava demais! Apanhei muito assim. Aí quando eu completei 16 anos, casei, aí logo eu já comecei a sofrer com meu marido, que bagunçava, tal. Assim. Depois sofri com meu menino internado, tudo isto aí, ó, tudo. Quer dizer, da minha parte eu não tive uma vida assim, boa, né? Agora, né? Mas agora eu já estou cheia de problema já!

Ao construir no grupo a explicação de que, assim como aconteceu com seus filhos, seus problemas se explicam em função da vivência de sofrimentos no passado, Roberta reforça uma visão pessimista acerca de suas possibilidades de mudança. Segundo ela, agora que ela tem uma vida melhor, já "está cheia de problema". Há pouca participação do grupo ao longo de seu relato, com exceção de breves intervenções do terapeuta. Neste momento interativo, a explicação do problema como tendo origem no passado pareceu limitar as possibilidades de ação no grupo. 
b) A doença mental como decorrente de dificuldades ou conflitos atuais.

O sentido de que suas queixas encontram-se associadas à vivência de problemas no cotidiano, em especial problemas de relacionamento familiar ou conjugal, foi construído pelos participantes em diversas trocas grupais. Este sentido apareceu mais freqüentemente nas falas de Ana Maria, Valter, Roberta, João e Rosilene. Geralmente, a discussão do problema como estando relacionado à vivência de dificuldades ou conflitos atuais de relacionamento favorecia uma maior interação dos participantes, que buscavam ajudar através de conselhos e sugestões. A noção de mudança associada a este sentido remetia à solução das dificuldades vivenciadas no momento.

Exemplo: Na sessão 9, Ana Maria queixa-se ao grupo de que sua depressão está relacionada à mudança de sua filha para sua casa, com o genro e os netos. Diz que a filha não tem responsabilidade, que assumiu muitas dívidas e questiona se a ajuda que dá a ela é válida. O grupo dá conselhos de como Ana Maria poderia solucionar o problema com a filha, para que ela possa melhorar.

Ana Maria: Desde que ela [filha] chegou que eu não fiz mais vestibular, porque eu não tenho as condições de estudar! (...) Então, eu queria retomar a minha vida, eu não tenho mais o compromisso de ficar buscando e levando criança na escola! (...) E isto me deixa doente! Quando ela chegou, que ela falou que ela ia trabalhar, que eu ia ficar cuidando das crianças, eu falei: "pelo amor de Deus, Priscila, não faz isto comigo que eu não vou agüentar!". Foi justamente o que aconteceu. Foi quando eu comecei com a minha depressão. (pausa) E agora eu tô presa de novo.

Marli: Ela tem que parar de fazer dívida pra ela poder ficar em casa.

Irene: Então, mas ela tá endividada, já, como ela tá explicando aí, né?

Ana Maria: Eu nunca fiz uma dívida dessa! Eu sempre planejei a minha vida, sempre fiz tudo planejado. Agora ela vai fazendo assim, as torto e às direita.

João: Este é o ponto que eu queria chegar. Ela também sabe que você vai dar a cobertura, então faz errado, né? Ela não tá te poupando, ela não tá te poupando!

Valter: Agora no caso dela, eu não sei, mas eu acho que a ajuda que ela tem dado, ela tem dado ajuda, e assim, a ajuda talvez está prejudicando eles. Talvez a ajuda mesmo seria orientar eles a pegar o carro, é novo, ver quanto eles deu de entrada, ver quantos meses eles já pagaram, e vai lá na firma que for, pede uma condição, que devolva parte do dinheiro, e que vai diminuindo um pouco da dívida!

Terapeuta: Mas vejam, as formas como ela vai lidar com isto são muitas, né? Cada um dá um conselho aqui, né? Mas como você vai lidar com esta situação a gente não sabe. Mas o que a gente pode lidar aqui é com este sentimento que você trouxe de que por mais que você ajude, você viu que a sua ajuda toma outro rumo. Agora você precisava ajudar a sua filha a não depender mais de você. E até quando você vai ficar abrindo mão do que você queria fazer? Isto é que está te incomodando, isto é o que dá pra perceber no que você começa a falar aqui.

Ana Maria: Eu engordei depois de tudo isto...

Terapeuta: Descompensou tudo...
Ana Maria: A gente começa a tomar um monte de remédio, né?

Numa ação-conjunta de produção de sentidos, Ana Maria e os demais participantes constroem a explicação de que ela está doente (depressão) por causa das dificuldades que vivencia com a filha. Bastante participativos, os integrantes do grupo fazem apontamentos e dão conselhos sobre como ela poderia modificar sua situação, através de uma mudança em suas atitudes. A possibilidade de melhora aparece articulada, neste momento interativo, à resolução do conflito atual, e o grupo é ativamente construído como recurso de ajuda - contexto para encontrar uma solução.

\section{c) A doença mental como decorrente de características pessoais.}

Aqui, a queixa aparece referida a aspectos individuais, como personalidade (comportamentos, gênio difícil, etc); diferenças individuais, que fazem com que algumas pessoas tolerem mais decepções ou frustrações do que outras; um "ponto fraco", que quando atingido leva ao adoecimento. Geralmente, este sentido não era referido pelo participante que apresentava a narrativa de problema no grupo, mas através de questões ou reflexões de outros participantes, sobretudo de João, Marta, Irene, Ana Maria e Valter. Esta explicação aparecia em momentos de grande participação, e remetia à responsabilização pessoal pela própria mudança.

Exemplo: Marta, na sessão 15, queixa de suas dificuldades com os pais, referindo-se à raiva que sentia deles e entendendo que eles eram os culpados por ela ter adoecido mentalmente. Valter questiona esta explicação, sugerindo que os problemas que ela vivencia com os pais também estão relacionados à sua própria personalidade.

Marta: Então, (...) tem hora que me pesa muito eu não perdoar os inimigos, e eu não sei perdoar, e tem hora que me pesa. Tem hora que eu falo; "ah, que me importa, eu não perdôo ninguém, eu não vou ser perdoada, e o que me importa?" Deste jeito! Tem hora que eu penso assim, uma hora eu penso de um jeito, outra hora eu penso de outro. Eu tô meio desequilibrada, o senhor está entendendo? Por causa disso, pra mim é disso.

Valter: Mas tenta seguir o lado espiritual e dar o perdão para as pessoas, porque ao passo que você vai perdoando Deus vai perdoar. E você perdoando os seus inimigos, eles vão se tornar amigo seu (...) Seria melhor pra você, porque você já pensou? Você passa por cima de um cisco e não limpa a casa, você age de um jeito assim, que se nós, eu no meu caso, se eu tivesse que te dar um pão, eu já ia pensar duas ou três vezes pelo que você mesma tá falando! (...) Então, eu observando, eu chego a fazer um quadro mental da pessoa que você é! Certo? (...) então, eu vejo pelo que vocêfala, que eu fico analisando, vou pensando, vou ouvindo e eu vejo que você tem um coração difícil de lidar! Talvez, eu não sei onde você mora, não sei nada a seu respeito, seus pais podem ser ruim, mas você também tem um coração difícil! Então quer dizer, dois corações difíceis, não é fácil. E você vai enfrentar isto, porque vai ficando esgotada, você vai pensando que tá certa, seus pais pensam que estão certo...

Marta: Não, eu não penso que tô certa não (parece brava, irritada). Minha consciência me acusa de tudo o que eu tô fazendo errado, mas eu não consigo. 
Valter: Não consegue mudar, né? Mas enquanto você não mudar, você não melhora...

A explicação de Valter de que o problema de Marta está relacionado aos seus problemas pessoais (modo de agir, gênio difícil), marca a construção do sentido de que ela precisa mudar suas atitudes e comportamentos em relação aos pais. Aqui, a possibilidade de mudança requer um reconhecimento de sua própria participação na criação do conflito (enquanto não mudar seus comportamentos, não vai melhorar).

\section{d) A doença mental como decorrente de uma criação da} mente ou da imaginação.

Este sentido aparece associado a descrições da doença como uma criação mental, proferidas sobretudo por Marli e Roberta, que apontam que seus problemas resultam do fato de pensarem demais ou "colocarem coisas na cabeça", e por Valter, que afirma a influência da mente na formação dos sintomas (doenças psicossomáticas). Aqui, a posição assumida pelos participantes é a de que não são propriamente doentes, apesar dos sintomas que apresentam. Geralmente, uma maior interação entre os participantes envolve a discussão deste sentido e a possibilidade de melhora aparece relacionada a um desejo e determinação pessoal para controlar os próprios pensamentos.

Exemplo: Na sessão 02, Marta afirma ter uma doença mental, mencionando os diagnósticos que recebeu ao longo de seu tratamento. Na conversação grupal, Valter questiona sua descrição de si, mostrando a possibilidade de que não exista uma doença orgânica e de que seus sintomas sejam, na verdade, uma criação da mente.

Marta: Não, mas eu li (a bula), eu li e tava escrito assim: "vai regredir os sintomas". Aí que eu tomei mais animada, porque eu pensei, não tem problema. Eu sou uma esquizofrênica, mas aí eu vou tomar remédio, mas vai regredir os sintomas, eu não vou ser curada pelo remédio, mas eu vou melhorar. (...) Aí no retorno eu perguntei pra médica, no retorno pra pegar outra receita eu perguntei pra médica: "Dra. Cira, eu tenho esquizofrenia?". Aí ela falou assim: "é, pode ser, né, em grau baixo, né?"

Valter: Mas, um momentinho, o remédio só dizia que era pra este tipo de doença?

Marta: Esquizofrenia.

Valter: Só pra isso? Porque os medicamentos às vezes serve pra...

Marta: Não, esse remédio é pra esquizofrenia, ajuda na depressão e reduz os sintomas.

Valter: Mas será que tem a doença mesmo?

Marta: Eu tenho.

Valter: Assim, será que se você vê o sintoma, você acha que tem a doença? Por que você desconfia do sintoma...

Marta: Mas, ué, ai, tendo o sintoma...

Valter: Se eu te falar uma coisa você não vai acreditar. Eu tive um problema sério de hemorragia no estômago, e tive que ficar em tratamento. E eu tinha hemorragia mesmo, precisei ir para o hospital, tal... No começo eu não aceitava, eu não sabia o que era hemorragia, se era grave, ou não, porque às vezes ficava com duas semanas de hemorragia. Enfraqueci muito. Então eu passei muito mal, e fui pra hospital, eu já tinha perdido a consciência. Aí eu fiquei tão traumatizado que não podia nem pensar em sentir uma dorzinha no estômago, que eu achava que eu ia ter hemorragia. Aí era doença mental. Aí eu ficava brigando com a cabeça falando pra ela que eu não ia ter hemorragia, que eu não tava com problema no estômago, tal, certo? Aí começava a ter sintomas de diarréia, porque se eи obrasse, еи ia olhar as fezes e se não tivesse com sangue a cabeça com certeza ia aliviar. Olha só! O sintoma pode enganar a gente...

Ao questionar a explicação de Marta de que ela tem uma doença mental (esquizofrenia), Valter introduz o sentido de que o sintoma pode ser uma criação da mente. Para Valter, a doença mental é o próprio descontrole da mente, que cria uma doença que não existe organicamente. Nesta interação, a melhora passa a ser significada como a possibilidade de controlar a própria mente e de não se deixar enganar por esta.

e) A doença mental como tendo uma causa orgânica.

Aqui, as queixas relatadas são vistas como produto de uma doença mental, descrita ora por termos médicos (diagnósticos), ora por expressões de senso comum (nervos abalados, hormônios que atuam no cérebro). Esta concepção de doença como tendo uma causa orgânica (não emocional) é referida em diversos momentos, sobretudo quando os participantes encontram dificuldades de compreender suas queixas. Este discurso apareceu em momentos de maior interação grupal, e seu uso fortaleceu um discurso pessimista em relação às possibilidades de mudança.

Exemplo: Na sessão 06, Marli refere no grupo o fato de ter se perdido ao tentar encontrar o ponto de ônibus e se queixa de esquecimento, de ver vultos, de distração. A partir do exemplo de Marli, Ana Maria fala de sua dificuldade de entender a causa de seus problemas, apontando para possíveis fatores orgânicos.

Marli: Eu não quero ver aquilo, eu não tô olhando... Eu tenho medo, viu?

Terapeuta: A história do gato?

Marli: Um gato, uma sombra, um vulto... E é deste lado (aponta lado direito).

Ana Maria: Ai, doutor, eu queria tanto entender o que se passa na cabeça da gente, viu?

Terapeuta: Eu também... (tom brincalhão)

Ana Maria: (ri, mas apresenta os olhos cheios de lágrimas) Que eu fico ouvindo estas histórias, e de repente a gente lembra que já aconteceu com a gente. Por que?

Terapeuta: De ficar vendo vulto?

Ana Maria: É, estas coisas que ela está falando, né? De ver um vulto... De repente acontece comigo também. Então que tipo de hormônio nosso cérebro produz, ou produz muito, ou produz menos, por que que a gente fica assim?

Terapeuta: De ficar vendo vulto?

Ana Maria: Ah, não só, esta irritação que a gente tem...

Marli: Uma agonia, uma coisa ruim, né?

Ana Maria: Ansiedade, esta dor no peito (já está chorando bastante neste momento). Ai, não sei viu? Às vezes eu fico pensando o que que eu poderia fazer pra melhorar, sabe? Eu acho que só o fato da gente tá aqui a gente tá procurando uma saída, né?

Terapeuta: Já está fazendo alguma coisa. 
Ana Maria: Mas, o que que eu posso fazer? Eu preciso ficar procurando esta resposta sozinha. Eu pego um livro, mas eu não acho a resposta... (chorando bastante).

Aproximando sua experiência da descrição de Marli, Ana Maria fala de seu desejo de compreender seu problema. Aponta a possibilidade de que seu problema seja causado por uma disfunção hormonal e, na interação com o terapeuta, fala de sua dificuldade de encontrar uma resposta que esclareça seu entendimento, parecendo não vislumbrar chances de melhora. A explicação da doença mental como tendo uma causa orgânica leva Ana Maria à busca por um conhecimento especializado acerca da mesma (procura as respostas nos livros, mas não encontra).

\section{f) A doença mental como decorrente de problemas sociais ou econômicos.}

Por fim, o sentido de que problemas sociais ou econômicos, como violência, assaltos e dificuldades financeiras, guardam relação com os sintomas apresentados também emergiu nas trocas conversacionais do grupo, especialmente nos enunciados de Marli, Valter, Roberta e Rosilene. Este sentido geralmente se constrói em momentos de maior interação grupal e está associado à visão de que suas possibilidades de mudança dependem também de uma mudança nos aspectos sociais / econômicos que causam seus problemas.

Exemplo: Na sessão 03, Valter e Marli referem que aspectos sociais estão relacionados ao desenvolvimento dos sintomas que apresentam, como nervoso e ansiedade.

Valter: Agora um detalhe importante: Ribeirão Preto, realmente, tá difícil de viver. Eu mesmo se pudesse ficar numa cidadezinha bem pequena, uma cidade mais calma, eu ia querer um pouquinho mais de tranqüilidade. Talvez eu teria outros problemas, mas seria melhor, porque a vida que a gente tá levando em Ribeirão Preto - agitada, violência.

Marli: As escolas tão uma sujeira, né? Nossa!

Valter: Todo tipo de coisa, certo? Fui assaltado duas vezes, inclusive roubaram já duas motos, outra que me roubaram...

Marli: Meu filho também tá pagando uma moto que roubaram dele...

Valter: Então quer dizer, a gente fica convencido de que precisa ter um pouquinho mais de segurança, e fala: “vou pelo menos comprar um carro, porque tinha uma motinha velha". Comprei uma motinha velha pra não chamar atenção do ladrão. Aí, os filhos começam a sair, porque eu tenho há dois filhos já de maior. Filho começa a sair a noite, ou vai na casa de namorada, ou quer fazer alguma coisa, vai de moto, a gente fica preocupado. (...) É tanta imprudência, tanta falsidade e tanta impunição. (...)

Marli: Então como que este pessoal vai sarar se... Por isso que eu não gosto da cidade, porque lá na roça não tem perigo. (...) Segurança? Temos segurança?

Valter: Olha, devido a tanto problema que surge, que a gente pra solucionar os problemas, evitar ver o filho da gente a pegar e entregar a chave pro ladrão assim, na calma, pensando que o seguro talvez pague, porque depois, o seguro paga... (...) Então pra que a gente veja os filhos da gente chegar em paz, a gente começa a fazer uma série de dividas, de problemas e mais coisa e mais coisa, que chega um ponto que a gente vive trabalhando e comprando, e fica quase desesperado pra tentar trazer paz numa casa! Quer dizer, é complicada a vida...

Marli: Você escutou aquela história, do homem que pôs fogo nos filhos, que queimou o apartamento? A mulher tá no hospital, os quatro morreram carbonizado.

Terapeuta: Mas veja, eu acho que a nossa conversa sobre o que estava acontecendo com as crises da Roberta tomou um rumo aí que, fora do nosso controle, porque a gente não vai poder fazer nada contra a violência que tá aífora dentro de nosso grupo...

Marli: Mas é isso aí que deixa a gente doente!

Marli e Valter trazem, no exemplo acima, relatos que apontam como as dificuldades sociais (violência, dificuldades financeiras) que vivenciam em seu cotidiano os afetam emocionalmente (causando preocupação, os deixando doentes). Neste momento interativo, a solução de suas queixas (ansiedade, nervoso, etc) fica atrelada à possibilidade de resolução de tais dificuldades que, como aponta o terapeuta, transcende as possibilidades de ajuda do grupo.

No Quadro 2, apresentamos uma síntese dos sentidos de doença mental que construímos em nossa análise, articulados aos padrões de interação e às expectativas acerca do tratamento propiciadas através do uso destes sentidos.

Quadro 2. Relação entre os sentidos de doença mental negociados no grupo, visão de mudança e padrão interativo nas trocas dialógicas grupais

\begin{tabular}{lllll}
\hline \multicolumn{1}{c}{ Sentido de doença } & & \multicolumn{1}{c}{ Visão de mudança } & \multicolumn{1}{c}{ Modos de interação } \\
\hline $\begin{array}{l}\text { a) A doença mental como decorrente de } \\
\text { experiências de sofrimento passadas }\end{array}$ & $\leftarrow \rightarrow$ & Dificuldade/ impossibilidade de melhora & $\leftarrow \rightarrow$ & $\begin{array}{l}\text { Longas narrativas pessoais. Pouca } \\
\text { interação grupal }\end{array}$ \\
\hline $\begin{array}{l}\text { b) A doença mental como decorrente } \\
\text { de dificuldades de relacionamento ou } \\
\text { conflitos atuais }\end{array}$ & $\leftarrow \rightarrow$ & $\begin{array}{l}\text { Necessidade de resolver os conflitos e } \\
\text { problemas atuais }\end{array}$ & $\leftarrow \rightarrow$ & $\begin{array}{l}\text { Maior participação grupal, através de } \\
\text { conselhos e sugestões }\end{array}$ \\
\hline $\begin{array}{l}\text { c) A doença mental como decorrente de } \\
\text { características pessoais }\end{array}$ & $\leftarrow \rightarrow$ & $\begin{array}{l}\text { Responsabilidade pessoal pelo próprio } \\
\text { tratamento e possibilidade de mudança }\end{array}$ & $\leftarrow \rightarrow$ & $\begin{array}{l}\text { Maior participação grupal, apontando a } \\
\text { necessidade de mudança pessoal }\end{array}$ \\
\hline $\begin{array}{l}\text { d) A doença mental como decorrente de } \\
\text { uma criação da mente ou da imaginação }\end{array}$ & $\leftarrow \rightarrow$ & $\begin{array}{l}\text { Responsabilidade pessoal pelas } \\
\text { possibilidades de mudança / Necessidade } \\
\text { de controlar os pensamentos, pensar } \\
\text { positivo, se preocupar menos }\end{array}$ & $\leftarrow \rightarrow$ & $\begin{array}{l}\text { Maior participação grupal, apontando } \\
\text { a necessidade de controlar a mente e os } \\
\text { próprios os pensamentos }\end{array}$ \\
\hline $\begin{array}{l}\text { e) A doença mental mental como tendo } \\
\text { uma causa orgânica }\end{array}$ & & $\begin{array}{l}\text { Dificuldade de melhora / limitação } \\
\text { do grupo enquanto recurso de ajuda/ } \\
\text { Conhecimento técnico }\end{array}$ \\
\hline $\begin{array}{l}\text { f) A doença mental como decorrente de } \\
\text { problemas sociais }\end{array}$ & $\leftarrow \rightarrow$ & $\begin{array}{l}\text { Dificuldade de resolução dos problemas } \\
\text { ou dificuldade / possibilidade de melhora }\end{array}$ & $\leftarrow \rightarrow$ & $\begin{array}{l}\text { Maior participação grupal, na tentativa de } \\
\text { entender a causa de seus problemas } \\
\text { dos problemas sociais }\end{array}$ \\
\hline
\end{tabular}




\section{Considerações Finais}

A partir da análise dos sentidos de doença mental negociados pelos participantes em suas trocas interativas (tempo curto), percebemos que estes recorreram a muitos dos discursos sociais que têm informado a construção social de sentidos de doença mental ao longo da história (tempo longo), descrevendo a si mesmos e aos outros de diferentes modos, de acordo com as demandas da interação em curso. O modo como cada pessoa participava da interação, privilegiando ou reforçando determinadas descrições da doença mental, guardava também relação com suas histórias conversacionais (tempo vivido), em que algumas destas descrições constituíram-se importantes.

Este último aspecto pode ser observado no Quadro 1, em que uma breve descrição das queixas referidas no momento do grupo e de seus diagnósticos encontra-se apresentada. A partir deste quadro, podemos refletir, por exemplo, sobre a influência da história de tratamento anterior na construção e sustentação de determinados sentidos de doença mental. Possivelmente, a participação neste contexto discursivo tenha instrumentalizado alguns participantes com um certo vocabulário (psicológico, psiquiátrico) para descrição de seus problemas. Nos exemplos aqui descritos, esta relação é mais visível nas falas de Valter, em que este descreve a doença mental como sendo decorrente de uma criação da mente, baseado em sua própria experiência (vai para o hospital achando que está com hemorragia); e de Marta, que descreve a doença mental como tendo uma origem orgânica e refere-se aos diversos diagnósticos que recebeu ao longo de sua história de tratamento psiquiátrico.

A partir de uma sensibilidade construcionista social e considerando a linguagem em seu caráter performático, destacamos, ainda, algumas implicações do uso destes sentidos para a interação imediata entre seus participantes e para a construção de sentidos de mudança (Quadro 2). Assim, através desta análise, podemos notar que grupo foi sendo construído como espaço conversacional de diferentes maneiras, criando diferentes possibilidades de significação para seus participantes.

É importante destacar que os diferentes sentidos de doença mental apresentados em nossa análise foram usados por diferentes participantes, em diferentes momentos, de acordo com as exigências imediatas do processo conversacional. Um mesmo participante poderia enfatizar o sentido da doença mental como tendo uma causa orgânica e, num outro momento interativo, trazer o sentido da doença mental como tendo origem em dificuldades vividas no passado. Sendo resultado de uma ação-conjunta entre os participantes do grupo, a produção e prevalência de um ou outro sentido dependiam do contexto conversacional e das possibilidades de significação conjuntamente criadas no grupo.

Esta ênfase no caráter local da produção de sentidos dificulta que as relações propostas no Quadro 2 sejam vistas de um modo estático e linear, resultando em conclusões generalizantes. A partir de um olhar estático sobre este material, poder-se-ia concluir, por exemplo, que uma vez que o discurso da "doença mental como decorrente de experiências de sofrimento vividos no passado" levava à limitação da emergência de narrativas de mudança, falar do passado no grupo não trazia benefícios terapêuticos. Por outro lado, entender-se-ia que situar a discussão do grupo em problemas atuais, levando o grupo à busca ativa por soluções, constituirse-ia, em si mesmo, um recurso terapêutico. Enfim, buscando relações lineares, este quadro poderia levar a conclusões fechadas, orientando técnicas terapêuticas e formas de ação em grupo. Estas conclusões desconsiderariam o processo conversacional como algo dinâmico e contextualmente situado. É na interação que reside o potencial criativo do processo de construção de sentidos e a possibilidade de construção conversacional da mudança, de modo que a ênfase recai menos sobre o conteúdo das conversas do que sobre o próprio processo conversacional, isto é, sobre o modo como se dá a negociação destes sentidos entre os participantes, no contexto específico desse grupo.

Refletir sobre o uso destes sentidos em contexto amplia nossas possibilidades de entendimento das relações apresentadas no Quadro 2. O grupo aqui estudado era oferecido na instituição sob a denominação de "grupo de apoio", tendo duração limitada (16 sessões). Esta descrição construía algumas expectativas em relação ao seu modo de funcionamento e objetivos, orientando também as interações entre seus participantes. A pergunta, então, torna-se: como o contexto de um grupo terapêutico, de curta duração e descrito com objetivos de apoio, sustentou determinados modos de conversa e interação entre seus participantes?

A construção da doença mental como decorrente de problemas vividos no passado, por exemplo, implicava que se construísse uma justificativa para tal entendimento. Isto só poderia se dar a partir da construção de histórias pessoais, nas quais a relação entre queixa atual e passado se apresentasse. Com isso, longas narrativas eram contadas no grupo e a postura do grupo era basicamente de escuta silenciosa. A possibilidade de apoio, objetivo primeiro do grupo, era, então, dificultada pela própria dinâmica conversacional. Se o problema atual resultava de vivências do passado, era importante falar dele, mas como dialogar com esta descrição? Nestes momentos interativos, o grupo se construía predominantemente como espaço de desabafo, onde a interação e diálogo entre os participantes ficavam em segundo plano. Esta "paralisia", por assim dizer, é condizente com a noção de que investigar as vivências do passado fugiria aos "objetivos" do grupo. Um aprofundamento das histórias pessoais deveria ser tema dos grupos psicoterapêuticos - modalidade de terapia de grupo de longa duração, voltada à maior compreensão interna, e também oferecida pela instituição.

Este mesmo tipo de reflexão pode justificar a participação ativa do grupo em torno das narrativas que traziam, como sentido predominante, a relação entre a queixa atual e a vivência de conflitos. Aqui, a busca por solução parecia investir os participantes de um senso de capacidade de ajuda, daí a ênfase nos conselhos e sugestões. Este modo de participar no grupo (oferecimento de apoio e a solução de conflitos) constituir-se-ia um objetivo possível a uma intervenção de tempo breve.

O sentido de que o problema estava relacionado a características individuais, também determinava algumas possibilidades de significação para o grupo. Esta ênfase nos aspectos individuais (personalidade, gênio, comportamentos pessoais) levava geralmente à patologização e culpabilização individual pelo problema descrito, sobretudo em se tratando de problemas 
de relacionamento (como aponta Valter em relação à Estela, no exemplo apresentado). A mudança, então, ficava dependente da aceitação da pessoa de sua dificuldade pessoal e da mudança em seus comportamentos, para que pudesse melhorar de suas queixas. $\mathrm{O}$ mesmo acontecia com o sentido de que a dificuldade era decorrente de uma criação da mente.

Ambos os sentidos remetem a noções bastante familiares no campo da Psicologia, onde ainda predomina a ênfase no indivíduo e a relação entre mudança e auto-conhecimento. Contudo, no contexto específico desse grupo de apoio e de curta duração, provavelmente a dificuldade de um aprofundamento no entendimento das questões individuais, fazia com que este discurso fosse utilizado para marcar, sobretudo, a importância de uma mudança de comportamento, sem necessariamente uma investigação sobre as questões pessoais e emocionais envolvidas na criação do problema, o que dava margens a culpabilização.

Também podemos refletir sobre as implicações do uso do sentido da doença mental como tendo uma causa orgânica nas conversações grupais. Considerando o contexto de um grupo de apoio, este tipo de descrição com freqüência gerava uma certa impotência no grupo, possivelmente em função da limitação da possibilidade de descrever o problema em função de seus aspectos psicológicos/ emocionais e, também, pela noção de gravidade que geralmente aparece atrelada à noção de "doença". Definir a doença a partir de termos técnicos dava à doença uma certa realidade, aproximando o grupo da condição de doentes mentais e dificultando a possibilidade de vislumbrar a construção conjunta de possibilidades de mudança. Enquanto doença orgânica, outros modos de tratamento poderiam ser mais efetivos do que a participação no grupo terapêutico, como o uso de medicação, por exemplo.

Por fim, o sentido da doença mental como decorrente de problemas sociais foi seguido, no contexto específico deste grupo, de grande participação. Aqui, parecia haver uma grande concordância dos participantes - pessoas com baixo rendimento, que viviam em bairros considerados pobres da cidade e que enfrentavam dificuldades sociais diversas - de que grande parte de suas queixas (preocupação, ansiedade, nervoso, irritação) não existiria se não vivessem em situação de carência de recursos financeiros e sociais. A possibilidade de se ter saúde mental aparece, aqui, associada à necessidade de se ter qualidade de vida. Contudo, estando pautado por concepções que focalizam o indivíduo como locus de atenção, neste grupo terapêutico, o sentido da doença mental como sendo causada por dificuldades sociais esvaziava a ação do terapeuta de grupo, e dificultava a possibilidade de construção de conversações em torno deste sentido de doença mental.

Considerando as proposições construcionistas, este tipo de reflexão acerca das implicações do uso da linguagem pode ser particularmente útil ao entendimento da terapia de grupo (Guanaes, 2004). Considerar os processos de produção de sentidos em seu caráter local, favorece o entendimento do grupo como um recurso conversacional, privilegiando-se os processos de negociação de sentidos entre seus participantes, a partir de uma perspectiva temporal (Spink \& Medrado, 1999), e o contexto em que este ocorre. Por meio deste tipo de reflexão, o terapeuta pode questionar a utilidade do uso destes discursos sociais (no caso, das explicações acerca da origem da doença mental) no contexto conversacional imediato, potencializando modos de conversa em desenvolvimento. Orientado por uma postura construcionista, o terapeuta pode refletir sobre: como determinados discursos emergem na ação conjunta entre os participantes do grupo? Qual a relação destes com o contexto social e as histórias conversacionais de cada participante? Que descrições identitárias e que visões de mudança estão sendo possibilitadas, sustentadas ou impedidas nas negociações em curso? Que descrições dificultam a participação coletiva? Que descrições favorecem tal participação? Como os participantes do grupo percebem as conversações no grupo, em diferentes momentos da sessão? Que outros modos de conversa podem ser mais úteis para o processo terapêutico e para a construção conversacional da mudança?

Mais do que um roteiro técnico, tais perguntas podem servir de recursos reflexivos para o terapeuta de grupo, em suas tentativas de construir aberturas e possibilidades mais dialógicas de relação entre os participantes do grupo - aspectos estes que têm sido apontado por diversos autores construcionistas (Anderson, 1997; Shotter \& Katz, 1998) como úteis aos processos de mudança terapêutica.

\section{Referências}

Anderson, H. (1997). Conversation, language and possibilities: A postmodern approach to therapy. New York: Basic Books.

Foucault, M. (1994). Doença mental e psicologia. (J. T. Coelho Neto, Trad.) Rio de Janeiro: Tempo brasileiro. (Trabalho original publicado em 1961)

Foucault, M. (1995). História da loucura na antiguidade clássica. (L. Shalders, Trad.) São Paulo: Perspectiva. (Trabalho original publicado em 1954)

Gergen, K. (1997). Realities and relationships: Soundings in social construction. Cambridge: Harvard University Press.

Guanaes, C. (2000). Grupo de apoio com pacientes psiquiátricos ambulatoriais: Exploração de alguns limites e possibilidades. Dissertação de Mestrado, Universidade de São Paulo, Ribeirão Preto.

Guanaes, C. (2004). A terapia como recurso conversacional: $O$ processo de negociação de sentidos em um grupo ambulatorial de curta duração em saúde mental. Tese de Doutorado, Universidade de São Paulo, Ribeirão Preto.

Pessotti, I. (1994). A loucura e as épocas. Rio de Janeiro: Ed.34.

Pessotti, I. (1996). O século dos manicômios. São Paulo: Ed.34.

Shotter, J. (2000). Conversational realities: Constructing life through language. London: Sage.

Shotter, J. \& Katz, A. (1998). 'Living Moments' in dialogical exchanges. Human Systems, 9(2), 81-93.

Spink, M. J. P. \& Medrado, B. (1999). Produção de sentidos no cotidiano: Uma abordagem teórico-metodológica para análise das práticas discursivas. Em M. J. Spink (Org.), Práticas discursivas e produção de sentidos no cotidiano: Aproximações teóricas e metodológicas (pp. 41-61). São Paulo: Cortez.

Recebido em 14.09.2004

Primeira decisão editorial em 04.04.2005

Versão final em 12.05.2005

Aceito em 11.07.2005 